\title{
Behavior of Burkholderia thailandensis (Burkholderia pseudomallei surrogate) in Acidified Conditions by Organic Acids Used in Ready-to-Eat Meat Formulations under Different Water Activities
}

\author{
Yohan Yoon* \\ Department of Food and Nutrition, Sookmyung Women's University, Seoul 140-742, Korea
}

\begin{abstract}
This study evaluated the antimicrobial effects of meat processing-related organic acids on Burkholderia thailandensis (Burkholderia pseudomallei surrogate) with different water activities. B. thailandensis KACC12027 (4 $\log$ CFU/mL) was inoculated in microwell plates containing tryptic soy broth $\mathrm{pH}$-adjusted to 4, 5, 6, and 7 with ascorbic acid, citric acid, and lactic acid and with water activities adjusted to $0.94,0.96,0.98$, and 1.0 with $\mathrm{NaCl}$, followed by incubation at $35^{\circ} \mathrm{C}$ for 30 h. The optical density (OD) of the samples was measured at $0,3,6,12,24$, and $30 \mathrm{~h}$ at $595 \mathrm{~nm}$ to estimate the growth of $B$. thailandensis. Growth of $B$. thailandensis was observed only at water activity of 1.0. In general, more bacterial growth $(p<0.05)$ was observed at $\mathrm{pH} 6$ than at $\mathrm{pH} 7$, and the antimicrobial effects of the organic acids on B. thailandensis were in the following order: Ascorbic acid $>$ lactic acid $>$ citric acid after incubation at $35^{\circ} \mathrm{C}$ for $30 \mathrm{~h}$. These results indicate that organic acids in meat processing-related formulations should be useful in decreasing the risk related to an emerging high risk agent (B. pseudomallei).
\end{abstract}

Key words: Burkholderia thailandensis, Burkholderia pseudomallei, dissociation constant

\section{Introduction}

Burkholderia pseudomallei is a Gram-negative bacterium which is usually isolated from soil, and the pathogen has been known to be related to melioidosis with significant morbidity and mortality up to $90 \%$ (Eoin West et al., 2008). This bacterium has recently brought attentions in food supply environments because $B$. pseudomallei shows broad host range and has caused disease in meat producing animals such as cattle, goats, and pigs (Sprague and Neubauer, 2004). In addition, animal-to-human transmission has also been reported, and most cases resulted in fatalities (Choy et al., 2000; Idris et al., 1998). Thus, the food contamination with B. pseudomallei is now considered as unavoidable (Dance, 2000). Li et al. (1994) also suggested that the meat from animals infected with B. pseudomalle $i$ would endanger the public health, and Zinchenko et al. (2008) recently conducted a study of $B$. pseudomallei on meat. In fact, there were melioidosis

*Corresponding author: Yohan Yoon, Department of Food and Nutrition, Sookmyung Women's University, Seoul 140-742, Korea. Tel: 82-2-2077-7585, Fax: 82-3-710-9479, E-mail: yyoon (a)sookmyung.ac.kr outbreaks caused by the ingestion of contaminated particles (Bassetti et al., 2005), drinking water (Inglis et al., 1998) and human breast milk (Ralph et al., 2004), and the recent risk assessment by Fosse et al. (2008) characterized B. pseudomallei as a bacterial hazard in European pork slaughter houses.

The number of infection cases with $B$. pseudomallei increase after flooding, and monsoon rainfalls are believed to be responsible for spreading $B$. pseudomallei, which leads to be a more severe infection in humans (Currie and Jacups, 2003; Ketterer et al., 1975). Taken together, it may suggest the possible ingestion of B. pseudomallei through animal origin foods such as pork and beef, especially for the region that has monsoon rainfalls. Therefore, the fate of $B$. pseudomallei needs to be studied under meat processing-related conditions. However, $B$. pseudomallei can be studied only in Biosafety Level (BSL)-3 facilities in many countries due to its high mortality rate (Bossi et al., 2004). Burkholderia thailandensis is genetically and morphologically very similar to $B$. pseudomallei, but it is not pathogenic to human (Qazi et al., 2008; Wuthiekanun et al., 1996), and B. thailandensis has also similar environment distribution with $B$. pseudomallei (Wuthiekanun et al., 1996; Yu et al., 2006). The 
differences between two species are only variations of arabinose-assimilation operon and the production of capsular polysaccharide (Haraga et al., 2008; Reckseidler et al., 2001). Hence, B. thailandensis has been used in recent studies related to physiological activities and pathogenic characteristics as a surrogate bacterium of B. pseudomallei (Haraga et al., 2008; Qazi et al., 2008; Thongdee et al., 2008; West et al., 2008; Yoon et al., 2010).

A variety of antimicrobials have been used to improve the food safety of manufactured foods (Feng et al., 2010). Most ready-to-eat meat products may contain various antimicrobials such as sodium chloride, lactic acid, nitrite and lactate/diacetate salts to inhibit Listeria monocytogenes growth (Glass et al., 1989; Mbandi and Shelef, 2002). In addition, the decrease of product $\mathrm{pHs}$ with organic acids such as ascorbic acid, citric acid, lactic acid, and acetic acid has been suggested in many studies to control pathogens. The previous studies by Calicioglu et al. (2002) and Yoon et al. (2005) showed that the treatments containing ascorbic acid, followed by heating at $60^{\circ} \mathrm{C}$ increased destruction of Escherichia coli $\mathrm{O} 157: \mathrm{H} 7$ in beef jerky slices. Recent studies also showed that the obvious antimicrobial effects of ascorbic acid and citric acid with chemical tenderizers on $E$. coli $\mathrm{O} 157: \mathrm{H} 7$ cells during marination at $4^{\circ} \mathrm{C}$ and cooking (Mukherjee et al., 2008, 2009; Yoon et al., 2009).

This study evaluated the antimicrobial activity of meat processing-related organic acids on emerging foodrelated agent (B. pseudomallei) using a surrogate (B. thailandensis) under different water activities.

\section{Materials and Methods}

\section{Preparation of inoculum}

B. thailandensis KACC 12027 (Korean Agricultural Culture Collection, Korea) stored as a frozen culture at $-70^{\circ} \mathrm{C}$ was cultured in $10 \mathrm{~mL}$ of tryptic soy broth (TSB; Difco, Becton Dickinson and Company, USA) at $35^{\circ} \mathrm{C}$ for $24 \mathrm{~h}$. The $0.1 \mathrm{~mL}$ of the culture was then transferred into 10 $\mathrm{mL}$ of TSB followed by subculture at $35^{\circ} \mathrm{C}$ for $24 \mathrm{~h}$. Stationary phase cells were serially diluted with a saline solution to obtain an inoculum size of $4 \log \mathrm{CFU} / \mathrm{mL}$.

\section{Treatments}

To prepare various organic solutions with different levels of $\mathrm{pH}$ and water activities, the $\mathrm{pH}$ of TSB was adjusted to 4, 5, 6, and 7 with ascorbic acid (Sigma-Aldrich Corp., USA), citric acid (Duksan Pure Chemical Co., Ltd., Korea) and lactic acid (Junsei Chemical Co., Ltd.,
Japan), respectively, and the water activity for each $\mathrm{pH}$ level of the solutions was adjusted to $0.94,0.96,0.98$, and 1.0 with $\mathrm{NaCl}$ (Duksan Pure Chemical). This resulted in a total of 16 combinations in a complete factorial design for each organic acid solution.

\section{Inoculation and measurement of optical density}

Each combination of organic acid solution was placed in wells of 96 micro-plate, and B. thailandensis was inoculated in each well to obtain $2 \log \mathrm{CFU} / \mathrm{mL}$. The microplates were then incubated at $35^{\circ} \mathrm{C}$ for $30 \mathrm{~h}$. The OD (optical density) values of the samples were repeatedly measured at $0,3,6,12,24$, and $30 \mathrm{~h}$ at $595 \mathrm{~nm}$ with a micro-plate reader (Bio-Tek ${ }^{\circledR}$, ELx 808, Korea).

\section{Statistical analysis}

This experiment was repeated twice with two samples in each repeat. The OD values in interactions among the fixed factors such as organic acid solutions, $\mathrm{pH}$, water activity and incubation time were analyzed by the mixed model procedure of $\mathrm{SAS}^{\circledR}$ version 9.2 (SAS Institute, Cary, USA). The type III F-test was used to remove random effects in the model at alpha $=0.05$ by the forward stepwise method, and the interaction effects of fixed effects and random effects were also examined in the type III F-test. Multiple mean comparisons among the interaction (organic acid $\mathrm{pH} \times$ water activity $\times$ incubation time) were performed with the pairwise $t$-test at alpha $=0.05$.

\section{Results and Discussion}

Bacterial growth of $B$. thailandensis was observed only 1.0 of water activity of solutions (F-value=864.0; $p<$ 0.0001) (Figs. 1-3). Thus, data are presented and discussed only for organic acids which had 1.0 of water activity in the text. Although bacterial growth was observed in some samples treated with organic acids, the growth appeared after $12 \mathrm{~h}$ of lag phase duration, regardless of the type of organic acid (Figs. 1-3).

In the conditions treated with ascorbic acid, only the samples adjusted to $\mathrm{pH} 6$ and 7 with the organic acid showed dramatic bacterial growth $(p<0.05)$ of $B$. thailandensis after lag phase duration, but not below pH 5 (Fig. 1B). However, $\mathrm{OD}_{595}$ values of $B$. thailandensis was significantly higher $(p<0.05)$ in $\mathrm{pH} 6$ of TSB broth $(0.625 \pm 0.078)$ than in TSB $(0.391 \pm 10.02)$ with $\mathrm{pH} 7$ after incubation at $35^{\circ} \mathrm{C}$ for $30 \mathrm{~h}$ (Fig. 1B). The similar result was also observed under the conditions of TSB treated with lactic acid, and higher $(p<0.05) \mathrm{OD}_{595}$ value $(0.156 \pm 0.022)$ was observed 

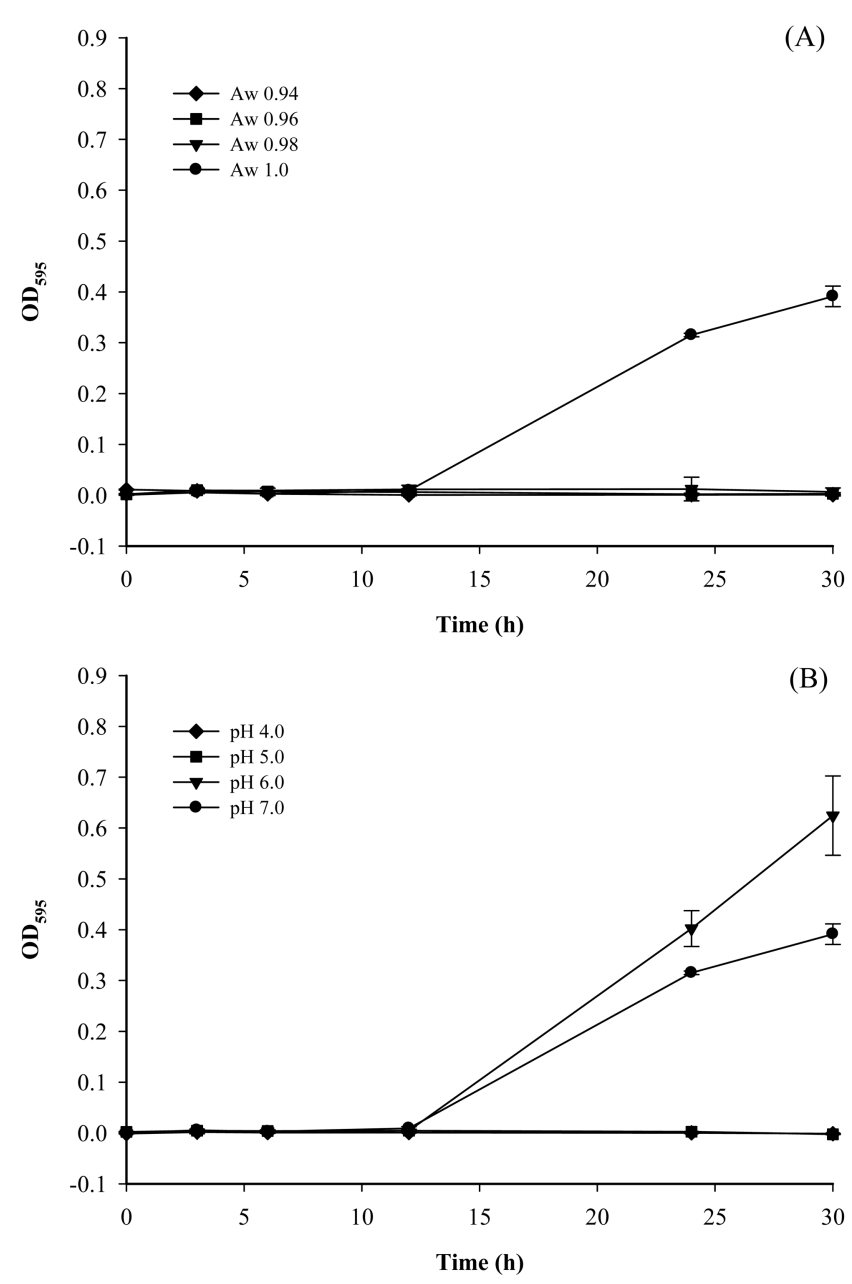

Fig. 1. Optical density (595 $\mathbf{~ m m})$ of Burkholderia thailandensis KACC12027 under different water activities at pH 7.0 of ascorbic acid (A) and under different acidified conditions by ascorbic acid at 1.0 of water activity (Aw) (B) during incubation at $35^{\circ} \mathrm{C}$ for $30 \mathrm{~h}$.

in the samples ( $\mathrm{pH} 5)$ adjusted with lactic acid than the one $(-0.003 \pm 0.001)$ adjusted with ascorbic acid to $\mathrm{pH} 5$ after incubation at $35^{\circ} \mathrm{C}$ for $30 \mathrm{~h}$ (Figs. $1 \mathrm{~B}$ and $2 \mathrm{~B}$ ). These results indicate that $B$. thailandensis can have more growth in acidic condition than in neutral condition, which was not observed in L. monocytogenes under the similar conditions (Yoon and Choi, 2010). This could be related to the pathogenic mechanisms of $B$. thailandensis. The bacteria uses type III secretion system to invade host, but type III secreted proteins such as BipD and BopE were detected only under acidic condition. Moreover, $B$. thailandensis under acidified environment ( $\mathrm{pH} 4.5)$ induced the capability of the bacterium to invade human respiratory epithelial cells A549 (Jitprasutwit et al., 2010). The result showing more growth in $\mathrm{pH} 6$ than $\mathrm{pH} 7$ became more obvious in citric acid-treated samples (Fig. 3B). Interestingly, the samples treated with the organic
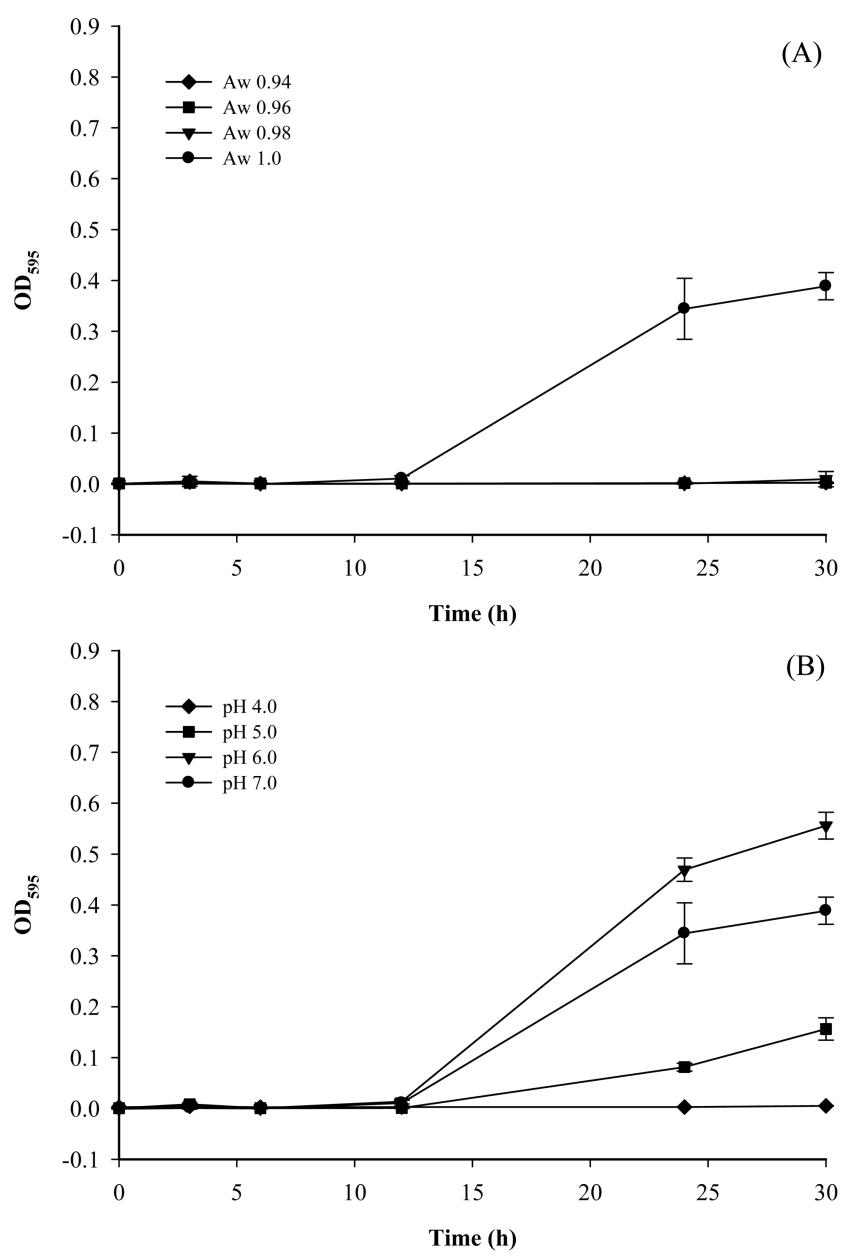

Fig. 2. Optical density $(595 \mathrm{~nm})$ of Burkholderia thailandensis KACC12027 under different water activities at pH 7.0 of lactic acid (A) and under different acidified conditions by lactic acid at 1.0 of water activity (Aw) (B) during incubation at $35^{\circ} \mathrm{C}$ for $30 \mathrm{~h}$.

acid to $\mathrm{pH} 5\left(\mathrm{OD}_{595}=0.753 \pm 0.083\right)$ had higher $(p<0.05)$ optical density, compared to the samples having higher $\mathrm{pH}$ values (Fig. 3B). The order of $\mathrm{OD}_{595}$ for the samples treated with citric acid was as follow; $\mathrm{pH} 5(0.753 \pm 0.083)$ $>$ pH $6(0.582 \pm 0.006)>\mathrm{pH} 7(0.386 \pm 0.009)$ at $35^{\circ} \mathrm{C}$ for $30 \mathrm{~h}$ (Fig. 3B).

Although the $\mathrm{pH}$ values of samples treated with different organic acids were at the same $\mathrm{pH}$ values, antimicrobial effects of the organic acids on $B$. thailandensis were ascorbic acid $>$ lactic acid $>$ citric acid (F-value $=107.86$; $p<0.0001$ ) (Figs. 1-3). This order was opposite to the order of the dissociation constants (citric acid: $7.510^{-4}>$ lactic acid: $1.3810^{-4}>$ ascorbic acid: $6.7610^{-5}$ ). Organic acids with lower dissociation constants have higher undissociated molecules. The undissociated molecules of organic acid permeate through the microbial cell membrane and dissociate into charged ions in the cytosol 


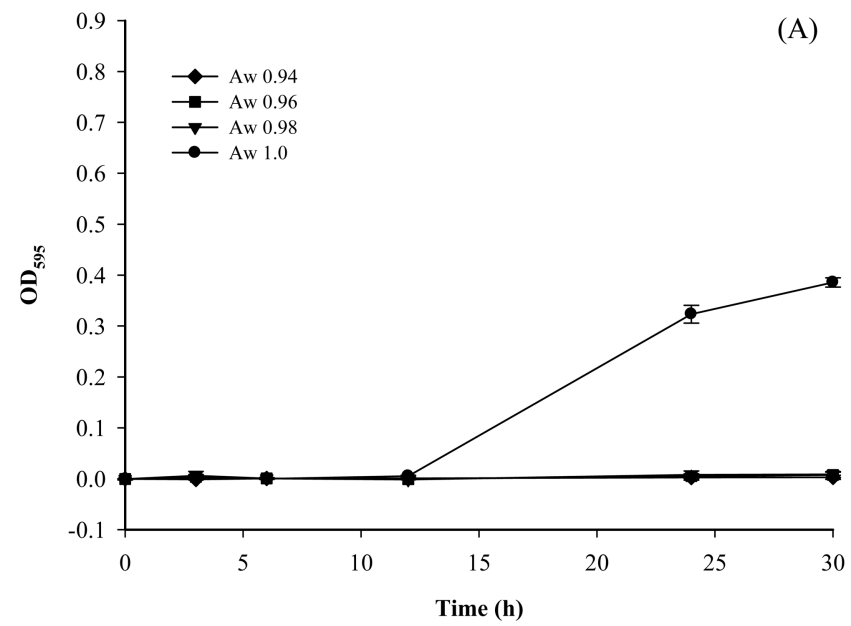

(B)

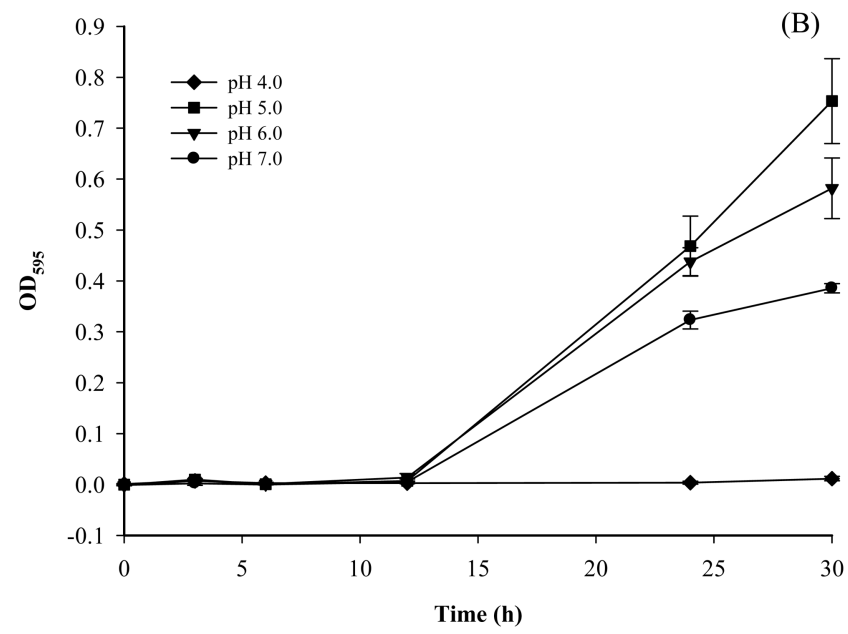

Fig. 3. Optical density (595 $\mathbf{n m})$ of Burkholderia thailandensis KACC12027 under different water activities at pH 7.0 (A) of citric acid and under different acidified conditions by citric acid at 1.0 of water activity (Aw) (B) during incubation at $35^{\circ} \mathrm{C}$ for $30 \mathrm{~h}$.

resulting in the cells to deplete energy reserves to pump out the ions across the plasma membrane (Booth and Kroll, 1989; Bracey et al., 1998). It is well known that the antimicrobial activity of organic acids is mainly associated with their undissociated state (Ahamad and Marth, 1989). Therefore, ascorbic acid showed more inhibition on the growth of $B$. thailandensis than lactic acid followed by citric acid.

In conclusion, use of organic acid in meat processingrelated formulation should be useful in decreasing the risk related to a emerging high risk agent (B. pseudomal$l e i)$ in food-related conditions, but level of acidification should be determined according to the dissociation constant of organic acid because some organic acid such as citric acid allowed even more growth of $B$. thailandensis at $\mathrm{pH} 5$.

\section{References}

1. Ahamad, H. and Marth, E. H. (1989) Behavior of Listeria monocytogenes at $7,13,21$, and $35^{\circ} \mathrm{C}$ in tryptose broth and acidified with acetic, citric, or lactic acid. J. Food Prot. 52, 688-695.

2. Bassetti, S., Bischoff, W. E., and Sherertz, R. J. (2005) Route of infection in melioidosis. Emerg. Infect. Dis. 11, 638-639.

3. Booth, I. R. and Kroll, R. G (1989) The preservation of food by low pH. pp. 119-160. In Gould, G. W. (ed.), Mechanisms of Action of Food Preservation Procedures, Elsevier, London.

4. Bossi, P., Tegnell, A., Baka, A., Van Loock, F., Hendriks, J., Werner. A., Maidhof, H., and Gouvras, G. (2004) Bichat guidelines for the clinical management of glanders and melioidosis and bioterrorism-related glanders and melioidosis. Eur. Surveill. 9, E17-E18.

5. Bracey, D., Holyoak, C. D., and Coote, P. J. (1998) Determination of the intracellular $\mathrm{pH}\left(\mathrm{pH}_{\mathrm{i}}\right)$ of growing cells of Saccharomyces cerevisiae: The effect of reduced expression of the membrane $\mathrm{H}^{+}$ATPase. J. Microbiol. Methods 31, 113125.

6. Calicioglu, M., Sofos, J. N., Samelis, J., Kendall, P. A., and Smith, G. C. (2002) Inactivation of acid-adapted and nonadapted Escherichia coli O157:H7 during drying and storage of beef jerky treated with different marinades. J. Food Prot. 65, 1394-1405.

7. Choy, J. L., Mayo, M., Janmaat, A., and Currie, B. J. (2000) Animal melioidosis in Australia. Acta Trop. 74, 153-158.

8. Currie, B. J. and Jacups, S. P. (2003) Intensity of rainfall and severity of melioidosis, Australia. Emerg. Infect. Dis. 9, 1538-1542.

9. Dance, D. A. (2000) Ecology of Burkholderia pseudomallei and the interactions between environmental Burkholderia spp. and human-animal hosts. Acta Trop. 74, 159-168.

10. Eoin West, T., Frevert, C. W., Denny Liggtt, H., and Skerrett, S. J. (2008) Inhalation of Burkholderia thailandensis results in lethal necrotizing pneumonia in mice: A surrogate model for pneumonic melioidosis. Trans. R. Soc. Trop. Med. Hyg. 102, S119-S126.

11. Feng, S., Zeng, W., Luo, F., Zhao, J., Yang, Z., and Sun, Q. (2010) Antibacterial activity of organic acids in aqueous extracts from pine needles (Pinus massoniana Lamb.). Food Sci. Biotechnol. 19, 35-41.

12. Fosse, J., Seegers, H., and Magras, C. (2008) Foodborne zoonoses due to meat: A quantitative approach for a comparative risk assessment applied to pig slaughtering in Europe. Vet. Res. 39, 01

13. Glass, K. A. and Doyle, M. P. (1989) Fate of Listeria monocytogenes in processed meat products during refrigerated storage. Appl. Environ. Microbiol. 55, 1565-1569.

14. Haraga, A, West, T. E., Brittnacher, M. J, Skerrett, S. J., and Miller, S. I. (2008) Burkholderia thailandensis as a model system for the study of the virulence-associated type III secretion system of Burkholderia pseudomallei. Infect. Immun. 76, 5402-5411. 
15. Idris, A., Rachmat, A. F. N., and Ali, S. M. N. (1998) Melioidosis: A case of sheep to human transmission. J. Vet. Malaysia 10, 77-79.

16. Inglis, T. J., Garrow, S. C, Adams, C., Henderson, M., and Mayo, M. (1998) Dry season outbreak of melioidosis in Western Australia. Lancet 352, 1600.

17. Jitprasutwit, S., Thaewpia, W., Muangsombut, V., Lulitanond, A., Leelayuwat, C., Lertmemongkolchai, G., and Korbsrisate, S. (2010) Effect of acidic $\mathrm{pH}$ on the invasion efficiency and the type III secretion system of Burkholderia thailandensis. J. Microbiol. 48, 526-532.

18. Ketterer, P. J., Donald, B., and Rogers, R. J. (1975) Bovine melioidosis in south-eastern Queensland. Aust. Vet. J. 51, 395-398.

19. Li, L., Lu, Z., and Han, O. (1994) Epidemiology of melioidosis in China. Zhonghua Liu. Xing. Bing. Xue. Za. Zhi. 15, 292-295.

20. Mbandi E. and Shelef, L. A. (2002) Enhanced antimicrobial effects of combination of lactate and diacetate on Listeria monocytogenes and Salmonella spp. in beef bologna. Int. J. Food Microbiol. 76, 191-198.

21. Mukherjee, A., Yoon, Y., Belk, K. B., Scanga, J. A., Smith, G. C., and Sofos, J. N. (2008) Thermal inactivation of Escherichia coli $\mathrm{O} 157: \mathrm{H7}$ in beef treated with marination and tenderization ingredients. J. Food Prot. 71, 1349-1356.

22. Mukherjee, A., Yoon, Y., Geornaras, I., Belk, K. E., Scanga, J. A, Smith, G. C., and Sofos, J. N. (2009) Effect of meat binding formulations on thermal inactivation of Escherichia coli $\mathrm{O} 157: \mathrm{H} 7$ internalized in beef. J. Food Sci. 74, M94M99.

23. Qazi, O., Prior, J. L., Judy, B. M., Whitlock, G. C., Barrie Kitto, G., Torres, A. G., Estes, D. M., and Brown, K. A. (2008) Sero-characterization of lipopolysaccharide from Burkholderia thailandensis. Trans. R. Soc. Trop. Med. Hyg. 102, S58-S60.

24. Ralph, A., McBride, J., and Currie, B. J. (2004) Transmission of Burkholderia pseudomallei via breast milk in northern Australia. Pediatr. Infect. Dis. J. 12, 1169-1171.

25. Reckseidler, S. L., DeShazer, D., Sokol, P. A., and Woods, D. E. (2001) Detection of bacterial virulence genes by subtractive hybridization: identification of capsular polysaccharide of Burkholderia pseudomallei as a major virulence determinant. Infect. Immun. 69, 34-44.

26. Sprague, L. D. and Neubauer, H. (2004) Melioidosis in animals: A review on epizootiology, diagnosis and clinical presentation. J. Vet. Med. 51, 305-320.
27. Thongdee, M., Gallagher, L. A., Schell, M., Dharakul, T., Songsivilai, S., and Manoil, C. (2008) Targeted mutagenesis of Burkholderia thailandensis and Burkholderia pseudomallei through natural transformation of PCR fragments. Appl. Environ. Microbiol. 74, 2985-2989.

28. West, T. E., Frevert, C. W., Liggitt, H. E., and Skerrett, S. J. (2008) Inhalation of Burkholderia thailandensis results in lethal necrotizing pneumonia in mice: a surrogate model for pneumonic melioidosis. Trans. R. Soc. Trop. Med. Hyg. 102, S119-S126.

29. Wuthiekanun. V., Smith, M. D., Dance, D. A., Walsh, A. L., Pitt, T. L., and White, N. J. (1996) Biochemical characteristics of clinical and environmental isolates of Burkholderia pseudomallei. J. Med. Microbiol. 45, 408-412.

30. Yoon, Y., Calicioglu, M., Kendall, P. A., Smith, G. C., and Sofos, J. N. (2005) Influence of inoculum level and acidic marination on inactivation of Escherichia coli O157:H7 during drying and storage of beef jerky. Food Microbiol. 22, 423-431.

31. Yoon, Y. and Choi, K. H. (2010) Antimicrobial activity of oleanolic acid on Listeria monocytogenes under sublethal stresses of $\mathrm{NaCl}$ and pH. Korean J. Food Sci. Ani. Resour. 30, 717-721.

32. Yoon, Y., Kim, J. H., Byun, M. W., Choi, K. H., and Lee, J. W. (2010) Effect of gamma irradiation on Burkholderia thailandensis (Burkholderia pseudomallei surrogate) survival under combinations of $\mathrm{pH}$ and $\mathrm{NaCl}$. Rad. Phys. Chem. 79, 545-548.

33. Yoon. Y., Mukherjee. A., Belk. K. E., Scanga. J. A., Smith. G. C., and Sofos. J. N. (2009) Effect of tenderizers combined with organic acids on Escherichia coli O157:H7 Thermal resistance in non-intact beef. Int. J. Food Microbiol. 133, 7885.

34. Yu, Y., Kim, H. S., Chua, H. H., Lin, C. H., Sim, S. H., Lin, D., Derr, A., Engels, R., DeShazer, D., Birren, B., Nierman, W. C., and Tan, P. (2006) Genomic patterns of pathogen evolution revealed by comparison of Burkholderia pseudomallei, the causative agent of melioidosis, to avirulent Burkholderia thailandensis. BMC Microbiol. 6, 46.

35. Zinchenko, O. V., Antonov, V. A., Tkachenko, G. A., Altukhova, V. V., Zamaraev, V. S., Piven, N. N., Goloseev, A., Vasilev, V. P., Lomova, L. V., and Alekseev, V. V. (2008) Comparative assessment of DNA extraction methods for identification of glanders and melioidosis etiological agents by PCR. Zh. Microbiol. Epidemiol. Immunobiol. 1, 55-60.

(Received 2010.11.3/Revised 2010.12.3/Accepted 2010.12.6) 